\title{
Formal and Informal Russian Invitation: Context and Politeness Strategies
}

\author{
Gayane Vlasyan and Irina Kozhukhova \\ Chelyabinsk State University, \\ 129 Brat'yev Kashirinykh st.454001, Chelyabinsk, Russia
}

\begin{abstract}
Invitation is a speech act which is perceived differently across cultures. Understanding the pragmatics of invitation requires knowledge of the notion of politeness and politeness strategies which comprise culture specific elements. Politeness is realized in various discourses, social contexts and speech acts. The purpose of the study is to identify politeness strategies in Russian invitation in formal and informal contexts in three age groups and see how they correspond to the understanding of politeness in Russian communicative culture. The empirical data for the study were obtained through discourse completion tests with 101 participants (issuers of the invitation) of different age and social status as well as through ethnographic observation. The research is based on Discourse Analysis and Politeness Theory (Brown \& Levinson 1987; Larina2009, 2015; Locher 2006, 2013; Leech 2014; Mills 2003, 2017; Sifianou 1992; Terkourafi \&Kadar 2017; Watts 2003, among others). We used discourse analysis to analyze the impact of the social and cultural context on the performance of invitation, the descriptive method which was used to analyze the pragmatic functions of invitation, as well as contextual interpretation of this speech act and the method of quantitative data processing. The study revealed some differences between a formal and informal invitation concerning politeness strategies and linguistic means of its expression. It also showed that in Russian culture issuing an invitation is not perceived as a face threatening speech act; in the analysed social contexts the preference is given to direct invitation, and the inviter's imposition, as a rule, is perceived positively. The results contribute to a better understanding of Russian politeness and communicative style and can be implemented in intercultural pragmatics, intercultural communication and SL teaching.
\end{abstract}

Keywords: Invitation, speech act, politeness, (in) formality, sociocultural context, Russian

\section{For citation:}

Vlasyan, Gayane \& Kozhukhova, Irina (2019). Formal and informal Russian invitation: Context and politeness strategies. Russian Journal of Linguistics, 23 (4), 994-1013. doi: 10.22363/23129182-2019-23-4-994-1013. 


\title{
Формальные и неформальные приглашения в русском языке:
} контекст и стратегии вежливости

\author{
Г.Р. Власян, И.В. Кожухова \\ Челябинский государственный университет \\ ул. Братьев Кашириных, 129, 454001, г. Челябинск, Россия
}

\begin{abstract}
Аннотация
Приглашение часто считается угрожающим лицу речевым актом, однако оно воспринимается и реализуется по-разному в различных культурных контекстах. Для понимания прагматики приглашения требуется знание стратегий вежливости, которые имеют свои культурные особенности и содержат специфические элементы культуры, которые могут вызывать непонимание в процессе межкультурной коммуникации. Вежливость проявляется в различных дискурсах и социальных ситуациях. Цель данного исследования - выявить и описать наиболее продуктивные стратегии реализации речевого акта «приглашение» в формальном и неформальном общении в различных возрастных группах. Материалом исследования послужили ответы на вопросы дискурсивного теста 101 респондента, а также этнографические наблюдения. Теоретическая часть исследования основывается на теории дискурса и теории вежливости (Ларина 2009; Brown \& Levinson 1987; Larina 2015; Leech 2014; Locher 2006, 2013; Sifianou 1992; Terkourafi \& Kadar 2017; Watts 2003). Основными методами анализа послужили: дискурс-анализ, прагматический анализ, метод семантического описания и метод количественной обработки данных. Исследование выявило некоторые различия между формальным и неформальным приглашением в отношении стратегий вежливости и языковых средств его выражения. Оно также показало, как носители русского языка понимают вежливость и уместность приглашения на формальном и неформальном уровнях. Полученные результаты свидетельствуют о том, в русской лингвокультуре приглашение не относится к угрожающим лицу речевым актам: предпочтение отдается прямому приглашению, допускается воздействие говорящего на адресата, которое, как правило, воспринимается позитивно и не нарушает принципов вежливости. Результаты исследования способствуют лучшему пониманию русской вежливости и стиля коммуникации и могут быть использованы в межкультурной прагматике, межкультурной коммуникации, а также в преподавании русского языка как иностранного.
\end{abstract}

Ключевые слова: приглашение, речевой акт, вежливость, социальный контекст, формальное приглашение, неформальное приглашение, русский язык

\section{Для цитирования:}

Власян Г.Р., Кожухова И.В. Формальные и неформальные приглашения в русском языке: контекст и стратегии вежливости // Russian Journal of Linguistics. 2019. Т. 23. № 4. С. $994-1013$. doi: 10.22363/2312-9182-2019-23-4-994-1013.

- Приходи ко мне на день рождения.

Я родился - завтра. Не придешь - обижусь и ударю... К моему приходу гости были в сборе. (С. Довлатов)

\section{1. Введение: постановка проблемы}

Исследование проведено в русле дискурс-анализа, прагмалингвистики и теории вежливости. В отличие от формальных синтаксических исследований, в которых предложение исследуется как высказывание, вырванное из контекста общения, прагматика включает в круг рассматриваемых объектов адресата речи, 
ситуацию общения и прагматические компетенции говорящих, что значительно расширяет диапазон изучаемых проблем. С адресатом речи связаны, в первую очередь, проблемы понимания, интерпретации высказывания и те правила и принципы, которыми адресат руководствуется при выводе как поверхностных, так и скрытых или косвенных смыслов высказывания и подлинных целей говорящего, а также реакция адресата на высказывание говорящего (вербальная и невербальная, прямая и косвенная), т.е. перлокутивный эффект высказывания. Как отмечал Дж. Лич, задачей прагматики является объяснение отношений между смыслом (который часто описывается как «буквальное» или лежащее на поверхности значение) и иллокутивной силой (направленным речевым воздействием говорящего на слушающего) (Leech 1983: 30).

Необходимо отметить, что в литературе коммуникативным особенностям приглашений в русском языке уделено не так много внимания. Среди работ, посвященных этой теме, можно выделить статью А.А. Акишиной и Н.В. Формановской (1968 г.), в которой приводятся наиболее употребительные разговорные ситуативно-обусловленные формулы приглашений в русском языке, работы И.В. Кожуховой $(2010,2012)$, где рассматриваются структурно-синтаксические особенности оформления интеррогативных косвенных речевых актов, в рамках которых анализируется и приглашение. Т.В. Ларина и Е.Б. Щелчкова рассматривают русское приглашение в сопоставлении с английским, анализируя функционально-прагматические особенности приглашений в британской, американской и русской коммуникативных культурах и стратегии вежливости, используемые представителями этих культур (Ларина 2009а,б; Ларина, Щелчкова 2013; Щелчкова 2013, 2015).

С целью рассмотрения динамики исследования приглашения в русскоязычном поле мы провели анализ базы elibrary.ru на наличие публикаций, прямо или косвенно посвященных данному речевому акту. В поисковой задаче была обозначена формулировка «приглашение речевой акт», для актуализации исследования были установлены временные рамки - с 2015 по 2019 годы. Анализ публикационной активности, ограниченный поисковой задачей, выдает 14 результатов (по годам: 2015 год — две публикации, 2016 год — пять публикаций, 2017 год — две публикации, 2018 год - пять публикаций; за 2019 год информации еще нет). Обратим внимание, что в представленных работах русский язык практически не рассматривается (исключение составляет публикация Е.Б. Щелчковой (2015) по сопоставлению реплик отказа в приглашениях на русском и английском языках).

Англоязычный анализ проводился на ограниченном, но показательном pecypce — Journal of Pragmatics. Косвенно темы приглашения за анализируемый период (2015-2019 годы) рассматриваются (упоминаются) в 132 статьях, однако, если посмотреть релевантные публикации, то увидим, что непосредственно речевой акт приглашения анализируется в статьях одного тематического номера журнала (выпуск 8) за 2018 год, "Invitations and responses: the formation of actions across languages", в котором представлено 9 статей (рассматриваются приглашения на языке фарси, итальянском, китайском, финском; приглашения в телефонных разговорах, институциональном дискурсе). Славянские языки в данном выпуске не представлены. 
Поиск по ключевым словам «invitation, Russian» в sciencedirect.com дает 23 результата, при этом полного совпадения названий статьи с ключевыми словами не наблюдается. В целом, мы видим, что русский язык довольно слабо представлен в исследованиях, посвященных данному речевому акту.

В статье мы определим место приглашения в системе речевых актов, а также рассмотрим функционально-прагматические особенности русского приглашения в различных социальных контекстах.

\section{2. Речевой акт «приглашение» в системе речевых актов}

Основополагающей теоретической концепцией прагмалингвистики является теория речевых актов. В качестве конвенционального определения речевого акта (РА) принято считать следующее: «Речевой акт - целенаправленное речевое действие, совершаемое в соответствии с принципами и правилами речевого поведения, принятыми в данном обществе; единица нормативного социоречевого поведения, рассматриваемая в рамках прагматической ситуации. Основными чертами речевого акта являются: намеренность (интенциональность), целеустремленность и конвенциональность. Речевые акты всегда соотнесены с лицом говорящего» (ЛЭС 1990: 413).

В речевом акте участвуют говорящий и адресат, которые выступают как носители определенных, согласованных между собой социальных ролей, или функций. Участники речевого акта обладают фондом общих речевых навыков (коммуникативной компетентностью), знаний и представлений о мире. Если попытаться найти место приглашения в системе речевых актов, предложенной Дж. Сёрлем, в которой он выделял ассертивы (репрезентативы), директивы, комиссивы, экспрессивы и декларативы (Searle, 1976), то, на наш взгляд, приглашение можно считать гибридным речевым актом.

Особенность речевого акта «приглашение» заключается в том, что он предполагает действие слушающего в его собственных интересах или в интересах всех участников коммуникации. По данным Большого толкового словаря русского языка приглашение - это «просьба, предложение сделать что-либо, принять участие в чем-либо, заняться чем-либо или письмо, записка с просьбой прийти, приехать куда-либо, принять участие в чем-либо» (Большой толковый словарь русского языка 1998: 690). В то же время посредством приглашения говорящий обязуется выполнить предложенные действия в будущем, а также обязывает слушающего принять участие в этих действиях. Таким образом, приглашение можно рассматривать и как комиссивнылй, и как директивный речевой акт. Как правило, действие приглашающего (например, приглашение на ужин) считается выгодным для приглашаемого. Успешное приглашение зависит от того, примет ли адресат предложение, а также от того, выполнит ли адресант взятое на себя обязательство, что может потребовать определенной работы как со стороны приглашающего, так и со стороны приглашаемого лица.

Исследователи различают два типа приглашений: явные (истинные, искренние) и неявные (ложные, неискренние) (Wolfson1981; Isaacs\&Clark 1990; Bella 2009; Suzuki 2015). Когда приглашение является явным и искренним, оно, как 
правило, содержит конкретную информацию, такую, как указание времени и места, а также упоминание о планируемой деятельности, запрос информации о возможности адресата принять приглашение, его планах и намерениях. Считается, что если приглашение истинное, адресант может настаивать на нем, повторить приглашение в случае отказа, привести доводы для того, чтобы оно непременно было принято. Такое приглашение будет воспринято как подлинное. Неявное приглашение часто действует как показное приглашение (или ритуальное приглашение), которое кажется истинным, но на самом деле таковым не является. Такие приглашения не сопровождаются обсуждением деталей самого приглашения, подразумевается, что его не следует принимать всерьез. Поскольку цель показного приглашения фатическая, приглашающий и приглашаемый признают условность, даже если на первый взгляд приглашение кажется достаточно искренним. На прагматическом уровне такие приглашения представляют собой лишь выражения добрых намерений, и не более того. Их прагматическая функция демонстрация симпатии говорящего в отношении собеседника.

С точки зрения теории вежливости приглашение часто рассматривается как угрожающий лицу речевой акт, однако его восприятие и реализация являются культурно специфичными. Приглашение может быть рассмотрено в рамках негативной и позитивной вежливости. Так, в английской лингвокультуре, для которой характерны стратегии негативной вежливости, приглашение является угрожающим лицу речевым актом: основная стратегия английских коммуникантов сделать приглашение в максимально косвенной форме, не допустить прямого воздействия на собеседника, предоставить ему право выбора (см. Ларина 2009: 238-251). Этим обусловлено повсеместное использование в английском языке интеррогативных форм, не выполняющих функций вопроса. Подобная косвенность в приглашениях объясняется неприкосновенностью зоны личной автономии: настойчивость в английской коммуникации недопустима, так как она воспринимается как давление на собеседника и нарушение правил вежливости. Перформативный глагол invite используется крайне редко. Как пишет Дж. Томас, в английском языке нечасто встречается перформатив I invite уои (Я приглашаю тебя) для выражения акта приглашения (Thomas 1995: 47). В английской лингвокультуре использование императива также строго ограничено и встречается в основном в приказах. В других директивах императив практически не используется, для них характерны интеррогативные и условные формы (см., например, Lakoff 1972; Ervin-Tripp 1976).

Следует отметить, что не во всех лингвокультурах наблюдается подобная ситуация. Например, А. Вежбицкая (Wierzbicka 1991) отмечает, что, в отличие от английского языка, косвенные приглашения, выраженные интеррогативными конструкциями (наподобие английского Would you like to...?), являются неестественными для польского языка и могут быть не поняты ими как приглашения. Автор также отмечает, что позитивная вежливость характерна для сербского, испанского и русского языков. Действительно, в русской коммуникативной культуре приглашения делаются настойчиво, допускается давление на собеседника, что демонстрирует большое желание увидеть его. 


\section{3. Материал и методы исследования}

Материал для исследования был собран входе эксперимента, проведенного в виде моделирования диалогического дискурса. Нами ставилась задача выявить основные тенденции в реализации речевого акта «приглашение» на русском языке в разных возрастных группах и разных социальных контекстах (при равном и дистантном общении). Материалом исследования послужили ответы на вопросы дискурсивного теста 101 респондента. В эксперименте участвовали респонденты, относящиеся к трем возрастным группам: (1) «школьники» - учащиеся общеобразовательной школы ${ }^{1}$ в возрасте 13-15 лет; (2) «студенты» - молодые люди в возрасте 19-22 лет, обучающиеся в высших учебных заведениях; (3) «взрослые» - работающие люди, имеющие среднее или высшее образование и средний или средне-высокий социальный статус. Данные о количестве анкетируемых приведены в табл. 1. По возрастному составу группа «взрослые» включает информантов 23-72 лет. Нижняя возрастная граница частично пересекается с группой «студенты». Разница состоит в том, что группа «студенты» опрашивалась в стенах вуза, а «взрослые» (по нижней возрастной границе) - на рабочем месте. При заполнении анкеты онлайн статус определялся информантом с ремаркой, что «взрослые» приравниваются к работающим информантам либо информантам пенсионного возраста. Гендерные характеристики респондентов на данном этапе не учитывались.

Результаты анкетирования, безусловно, не являются ультимативными, тем не менее, выявляют важные тенденции в формировании речевого акта «приглашение» в русском языке.

Как показал анализ существующих работ, в лингвистических речеактовых исследованиях еще не были представлены анализируемые нами группы в их совокупности.

таблица 1

Группа анкетируемых по разным возрастным группам

\begin{tabular}{|l|c|c|}
\multicolumn{1}{c|}{$\begin{array}{c}\text { Группа } \\
\text { анкетируемых }\end{array}$} & $\begin{array}{c}\text { Количество } \\
\text { (человек) }\end{array}$ & $\begin{array}{c}\text { Абсолютное количество } \\
\text { (\%) }\end{array}$ \\
\hline Школьники & 21 & 20,8 \\
\hline Студенты & 37 & 36,6 \\
\hline Взрослые & 43 & 42,6 \\
\hline Итого & 101 & 100 \\
\hline
\end{tabular}

Для исследования различных регистров речевого акта «приглашение» (равностатусное и разностатусное) анкетируемым предлагалось ответить на два вопроса (по формулировке опросника):

(а) Представьте, что вы хотите пригласить друга / хорошего знакомого на вечеринку или день рождения. Сформулируйте свое устное приглашение и зафиксируйте его.

1 МАОУ «Образовательный центр «НЬЮТОН» г. Челябинска» 
(б) Представьте, что вы хотите пригласить начальника на мероприятие или день рождения. Сформулируйте свое устное приглашение и зафиксируйте его.

Ситуация (а) характеризуется статусной и социально-психологической симметрией, ситуация (б) характеризуется наличием вертикальной и социально-психологической дистанции.

Анкеты заполнялись взрослыми либо в бумажном виде, либо посредством сервиса Surveymonkey.com. Со школьниками и студентами работа шла при непосредственном контакте в рамках классных/кураторских часов. Основными общеи частнолингвистическими методами анализа полученного материала послужили метод дискурс-анализа, метод семантического (методика семантического описания, семантико-синтаксический анализ и др.) и прагматического анализа (непосредственная интерпретация речевого акта), экспериментальный, сопоставительный методы и метод количественной обработки данных.

Во время анализа полученных результатов особое внимание уделялось следующим аспектам: способу выражения, интенсификаторам/митигаторам, маркированной лексике, обращениям, а также дополнительным компонентам. Сводные результаты по каждому из рассматриваемых регистров приведены в таблицах в конце каждого раздела.

\section{4. Результаты исследования}

\section{1. Неформальное приглашение}

\subsection{1. Школьники}

При всем разнообразии конструкций в группе «школьники» в рамках равностатусной коммуникации на первый план по частотности выходит использование приглашения в побудительной форме - 64\%. При этом, кроме прямого императива, использовался императив совместного действия, ср.:

(1) Привет, бро! Приходи на вечеринку!

(2) Привет, мой лучший друг! Почли ко мне на вечеринку!

В рамках императивной группы особо выделяются формы с окказионализмом го, который является калькой с английского go (зд. идем! пойдем!). Данную форму использовала почти четверть (24\%) опрошенных:

(3) Дарово! Го ко мне домой!

(4) Привет! Саш, го завтра ко мне на вечеринку!

Из окказионализмов отмечаются также молодежные сленгизмы (днюха, погнали), в том числе американизмы типа бро, хей, являющиеся, на наш взгляд, маркерами внутригрупповой принадлежности, призванными сократить коммуникативную дистанцию и показать собеседнику, что «я свой»:

(5) Погнали ко мне на вечеринку!

(6) Дороу, го на мою днюху.

На вопросительные высказывания приходится 23\% всех ответов, что, с одной стороны, говорит о высоком потенциале вопросительных конструкций как в рав- 
но-, так и в разностатусном общении, а с другой - показывает довольно большую вариативность при использовании вопросов, чего не наблюдалось в императивах:

(7) Не хочешь ли пойти ко мне на вечеринку?

(8) Пойдешь ко мне на день рождения?

(9) Сможешь прийти ко мне на день рождения завтра?

(10) Сможешь ли ты заглянуть ко мне на вечеринку?

Конструкции варьируются от уточнения общего желания идти на мероприятие (с частицей «не») до выражения общей модальности («сможешь», «сможешь ли»), а также минимизации коммуникативного давления за счет использования глагола с меньшим прагматическим весом — «заглянуть» (т.е. зайти на короткое время, мимоходом).

Небольшую группу (4,4\%) составили высказывания в сослагательном наклонении, которые также смягчают воздействие на адресата, при этом сигнализируют о желании приглашающего:

(11) Я бы хотел пригласить тебя.

Перформативные высказывания также довольно редки $(8,6 \%)$, что объясняется неформальностью общения:

(12) Я приглашаю тебя на свою вечеринку.

(13) Я приглашаю тебя на мою вечеринку.

Из дополнительных элементов можно выделить:

а) интенсификаторы, описывающие желание приглашающего видеть приглашаемого и создающие дополнительные мотивационные условия, спекулируя системой ценностей приглашаемого:

(14) Привет, дружище! Приглашаю тебя на пижамную вечеринку. Обещуаю, будет весело!

(15) Привет, Даш! У меня вечеринка дома, будет весело, приходи обязательно!

(16) Привет, Олег! Я бы хотел пригласить тебя на мой день рождения. Будет много газявы!

б) отсутствие в анализируемых ответах маркера вежливости «пожалуйста», элементы вежливости либо включены в синтаксическое оформление приглашения, либо отсутствуют в принципе;

в) уточнение даты и места проведения - $28 \%$ респондентов.

Считаем важным отметить, что половина ответов содержала в себе прямую или имплицитную формулировку «приходи ко мне домой», в то время как обращает на себя внимание факт приглашения “не-домой” (кафе, парк, ТРК):

(17) Хей! Привет, я приглашаю тебя на свой день рождения (дата) в пейнтбол, в парк Гагарина, в 15.30 там.

\subsection{2. Студенты}

В данной группе также рассматриваются равностатусные приглашения. В половине случаев приглашение выражается прямым императивом (50\%):

(18) Приходи ко мне / Приходи сегодня / Приходи! 
Однако здесь на первый план выходит наличие вопросительной формы (не в самом теле приглашения, а в уточняющих формулировках) - 43\% всех приглашений: (mьl) придешь? / Что думаешь? / Присоединишься? / Ты свободна? / Не хочешь прийти?

Подобные формулировки имеют разный угрожающий лицу вес - от прямого вопроса «ты придешь?» до более пространной формулировки «что думаешь?».

Отметим также вопросительно-отрицательную конструкцию, традиционно ассоциирующуюся с повышенной вежливостью, но не находящую широкого применения в нашем материале. Частотным также является приглашение типа «описание ситуации + интенсификатор / императив / другой компонент (дополняющий элемент)»: Я тут решила организовать / Я устраиваю / Слушай, мьь хотим собраться... Буду рада видеть тебя там / Жду / Давай тоже!

Использование перформатива единично (2\%) («Приглашаю тебя»). 72\% всех приглашений данной группы формулируется с использованием различных интенсификаторов: очень хочу, чтобы ты пришла / буду ждать / отказ не принимается / приходи, будет интересно. К интенсификаторам также можно отнести апелляцию к старой дружбе — «мы так давно не виделись», интересам приглашаемого «как ты любишь», приятному времяпрепровождению — «будет интересно», «будет весело».

В данной группе, как и в группе «Школьники», выделяется использование сленгизмов. Наиболее частотными являются лексемы го и по(чиллить), несомненно представляющие собой маркеры внутригрупповой принадлежности: тупо почиллить / хэй, го тусить / подкатишь? / крутая идея / че, пойдем? / хаюшки / бро:

(19) Го ко мне.

(20) Тут туса намечается. Го?

(21) Сльишь, го тусить?

Среди маркеров внутригрупповой принадлежности на более частном уровне можно выделить обращения, употребляемые только в рамках данной группы, например, принцесска или ребятки. Данные случаи единичны.

\subsection{3. Взрослые}

Результаты анализа данной группы существенно отличаются от предыдущих. 67\% всех равностатусных приглашений в рамках рассматриваемой группы приходятся на перформативную конструкцию «Приглашаю тебя»:

(22) Приглашаю тебя на праздник! Буду рада тебя видеть!

(23) Дорогой...! Приглашаю тебя в гости, чтобь отметить нашу 50-летнюю дружбу.

(24) Маруся, приглашаю тебя на свой праздник! Жду!

На группу императивов приходится всего $28 \%$ :

(25) Девочки, приходите ко мне в гости домой. Отметим мой день рождения.

(26) Вера, жду тебя в субботу в гости, ко мне домой, часов в пять. Приходи.

(27) Привет, Серега, приходи в гости! 
Развернутые высказывания окказиональны. Своей формулировкой они интенсифицируют речевой акт и показывают желание приглашающего увидеть приглашаемого:

(28) Вася, друг! ...числа в...часов твое присутствие озарит нашу встречу. Уж я найду способ прекрасно провести время!

(29) Ирина, привет! Как дела, как детки? А у меня скоро день рождения. Мы с мужем решили собрать всех близких друзей на даче. Сможешь? 28 июня, часа в 2. С собой все приносят хорошее настроение! Как добираться - попозже договоримся. Как ты смотришь на такое приглашение?

Вопросительные формулировки также единичны (5\%):

(30) У меня во вторник день рождения. Придешь?

В равностатусных приглашениях обращают на себя внимание следующие детали:

в 54\% случаев при приглашении с упоминанием времени время указывается неточное:

(31) Приходи завтра вечером, поболтаем.

(32) Жду в пятнииу после работь.

(33) Жду тебя в субботу в гости, ко мне домой, часов в пять.

Вероятно, что при дальнейшем обсуждении деталей приглашения время будет уточнено, но в целом такой подход показывает достаточно расслабленное отношение к категории времени в равностатусном общении 2 .

В обращениях женщина-женщина (мужчины - окказионально) обращает на себя внимание использование вокатива дорогая (моя дорогая / дорогая подруга / дорогая + имя):

(34) Дорогая, чем занимаешься в субботу?

(35) Дорогой...! Приглашаю тебя в гости.

(36) Дорогая моя подруга! Приглашаю тебя к себе и жду с нетерпением, что ть придешь.

Приглашающие таким образом подчеркивают определенную душевность и интимность отношений. На наш взгляд, подобное обращение не является частотным для устной речи. Данные дискурсивного теста зачастую могут показывать экстраполяцию элементов письменной речи в устную (см., например, [Кожухова 2019]). Тем не менее, именно данная подгруппа характеризуется подобной отсылкой к сердечности.

Резюмируем результаты в виде таблицы ${ }^{3}$.

2 Г.В. Елизарова отмечает, что сейчас происходит трансформация отношения ко времени от «расслабленного» (полихронного) до «четкого» (монохронного) (Елизарова 2009).

${ }^{3}$ В таблице отмечены релевантные для исследования параметры. 
Власян Г.Р., Кожухова И.В. Russian Journal of Linguistics. 2019. Т. 23. № 4. С. 994-1013

Выражение приглашения в равностатусном общении

\begin{tabular}{|c|c|c|c|}
\hline \multirow[t]{2}{*}{ Параметр } & \multicolumn{3}{|c|}{ Группа } \\
\hline & Школьники & Студенты & Взрослые \\
\hline Императивные конструкции & $64 \%$ & $50 \%$ & $28 \%$ \\
\hline Вопросительные конструкции & $23 \%$ & $43 \%$ & $5 \%$ \\
\hline Сослагательное наклонение & $4,4 \%$ & $5 \%$ & Отсутствует \\
\hline Перформативы & $8,6 \%$ & $2 \%$ & $67 \%$ \\
\hline Интенсификаторы & $63 \%$ & $72 \%$ & $5 \%$ \\
\hline Митигаторы & $4 \%$ & окказионально & окказионально \\
\hline Уточнение даты/времени & $\begin{array}{l}28 \% \text { (из них } 18 \%- \\
\text { желание дать письмен- } \\
\text { ное приглашение) }\end{array}$ & окказионально & $\begin{array}{l}\text { 31\% (указание } \\
\text { на приблизитель- } \\
\text { ность времени) }\end{array}$ \\
\hline Лексические особенности & $\begin{array}{l}\text { американизмы, слен- } \\
\text { гизмы }\end{array}$ & $\begin{array}{l}\text { сленгизмы, амери- } \\
\text { канизмы. Апелляция } \\
\text { к длительности отно- } \\
\text { шений, интересам } \\
\text { приглашаемого, при- } \\
\text { ятному времяпрепро- } \\
\text { вождению/ Описатель- } \\
\text { ность ситуации }\end{array}$ & Обращения \\
\hline
\end{tabular}

Анализ речевого акта «приглашение» в равностатусных приглашениях показывает превалирование побудительной формы (группы «Школьники», «Студенты») и активное использование перформативов в группе «Взрослые». Использование митигаторов не является частотным ни в одной из выделенных групп. Напротив, в проанализированных контекстах широко используются интенсификаторы, акцентуализирующие желание приглашающего, а не приглашаемого (жду! / очень хочу тебя увидеть (у себя)! / твое присутствие обязательно / буду ждать с нетерпением / буду рада нашей встрече / отказ не принимается), что говорит об отсутствии угрожающего лицу потенциала в равностатусных приглашениях. Отметим также маркеры позитивной вежливости, сленгизмы/американизмы как маркеры внутригрупповой принадлежности в группах «Школьники» и «Студенты», маркеры интимности - в группе «Взрослые». Широкое использование императивов, перформативов, интенсификаторов подтверждает нашу идею о том, что речевой акт «приглашение» в русской коммуникативной культуре не относится к угрожающим лицу.

\section{2. Формальные приглашения}

Формальные приглашения рассматриваются в тех же группах, что и неформальные, но при разностатусных отношениях, характеризующихся наличием вертикальной дистанции.

\subsection{1. Школьники}

Разностатусные приглашения в группе «школьники» менее разнообразны по своим формам, 81\% всех приглашений приходится на перформатив (с подлежащим и без подлежащего):

(37) Мы приглашаем вас на фотовыставку!

(38) Я приглашаю вас на день рождения! 
Перформатив может дополняться деталями:

a) уточнение желания приглашаемого, служащее интенсификатором приглашения и представляющее определенную коммуникативную опасность:

(39) Здравствуйте, Ирина Владимировна, пригламаю вас на мой день рождения, noŭdeme?

б) уточнение возможности, смягчающее воздействие на адресата:

(40) Здравствуйте, я приглашаю вас..., если вы, конечно, не заняты.

Одинаковые по форме речевые акты (перформативные в данном случае), отягощаются дополнительными элементами с противоположным коммуникативным весом.

Считаем важным отметить, что 15\% респондентов данной группы указывают на предпочтение письменного приглашения:

(41) Взрослым я бы передал письмо с приглашением: Я хочу пригласить вас на праздник. В этом приглашении я указал бы дату и время.

Любопытной, на наш взгляд, также является ремарка одного из респондентов: «омой я бы не пригласил» - т.е. дом рассматривается как личная, приватная зона, куда допускаются только «свои» (= равностатусные). Данные факты могут быть интересны для дальнейших психо- и социолингвистических исследований.

Снижение коммуникативного давления, характерное для данного контекста, реализуется за счет вопросительно-отрицательных форм с частицами бы и ли. Митигативный эффект достигается также с помощью замещения глаголов посеmumb/nрийти на глаголы кратковременного действия зайти/заглянуть (по пути, мимоходом):

(42) Здравствуйте, не хотите ли вы зайти на мою фотовыставку?

(43) Здравствуйте, не хотели бы вы заглянуть ко мне на фотовыставку?

Из дополнительных компонентов (некоторые частично отмечены выше), выделяются:

а) интенсификаторы «буду очень рада»;

б) митигаторы «если вы, конечно, не занятыл».

В целом отметим значительное преобладание перформативов, при этом почти половина перформативов (вариант «местоимение + перформатив») выражена во множественном числе и имеет форму «мы приглашаем», что указывает на разностатусность общения и относительную невозможность пригласить человека, с которым коммуникант находится в дистантных отношениях, на личное мероприятие (за счет конструкции «мы + перформатив» приглашающий защищает свое коммуникативное лицо). Лексическое и синтаксическое разнообразие в случае субординативных отношений сводится к минимуму: используемые глаголы стилистически нейтральны («приглашать», «идти»), лексически однообразны (исключение - глагол «заглянуть») и синтаксически инвариативны.

Отметим также, что результаты данного исследования не являют собой полную и объективную репрезентацию, так как очевидно, что данные итоги, ско- 
рее всего, не будут характерны для начальной школы и для старших классов. Тем не менее, для нашего исследования важна не только тенденция в выражении приглашений в разностатусной коммуникации, но и возрастная эволюция речевого акта.

\subsection{2. Студенты}

В данной возрастной группе в разностатусных приглашениях предпочтение отдается конструкции с сослагательным наклонением (42\%), использование перформативных (30\%) и вопросительных конструкций (26\%) распределяется примерно одинаково, употребление императивной конструкции единично (2\%).

Приглашение с использованием сослагательных конструкций сводится к употреблению глаголов пригласить/предложить/nрисутствовать/видеть в формуле «Я + глагол в прошедшем времени + бы, чтобы...»:

(44) Я хотела бы, чтобы вы присутствовали...

Сослагательное наклонение говорит о желаемости действия, что, с одной стороны, интенсифицирует высказывание (говорящий говорит о своем желании), с другой - служит митигатором, так как желание выражено гипотетически, а не императивно. В целом следует отметить довольно низкое использование митигаторов в данной группе (17\%).

Вторая по частотности группа приходится на приглашения с использованием перформативных глаголов (30\%) по модели: «Уважаемый (имя) + (я) приглашаю Вас». Данная конструкция во всех случаях дополняется модификаторами: если (с)можете / я думаю, вам может быть это интересно / будет ли у вас возможность прийти? и др.

Также относительно частотными (26\%) являются вопросительные высказывания, традиционно сопряженные с вежливыми, коммуникативно-дистантными отношениями: Не хотите ли вы пойти / присутствовать / присоединиться? В них использована стратегия вежливости дистанцирования: приглашающий не информирует о своих желаниях, а интересуется желаниями или возможностями приглашаемого, предоставляя ему таким образом выбор:

(45) Не хотите ли Вы прийти на нашу фотовыставку?

(46) Сможете ли вы прийти?

(47) Будет ли возможность прийти? и др.

Прямой императив, случаи употребления которого единичны, сопровождается дополнительным компонентом:

(48) Приходите, будет интересно!

Среди дополнительных компонентов приглашения, которые в целом были употреблены более половиной респондентов (51\%), можно выделить те, что нацелены как на описание выгоды бенефицианта: будет интересно / получите массу новых впечатлений! / ...вам должно быть очень интересно там / ...я сльшал, вы увлекаетесь...я думаю, вам понравится, так и на интенсификацию важности принятия приглашения для приглашающего буду очень рад вас видеть / я буду очень рада / это было бы честью для меня! / мы вас ждем! 
Отличительной чертой данной возрастной группы является использование обращений (92\%). Они имеют стандартную форму (имя + отчество) и являются инициальной частью приглашения. Обращение может сочетаться с приветствием (наиболее частотное - «Здравствуйте!»):

(49) Здравствуйте, Светлана Анатольевна, мы хотели бы пригласить Вас на фотовыставку!

Окказионально указывалась необходимость дополнить устное приглашение письменным (приводилось в скобках, после непосредственного приглашения). Данные дополнения также служат индикаторами субординативных формальных отношений.

Полученные данные говорят о том, что в формальных контекстах вежливость дистанцирования в целом реализуется за счет статусного обращения по имениотчеству, частичной установки на интересы приглашаемого (создание дополнительной мотивации при описании выгоды). Однако наиболее характерными оказались перформативные конструкции, ориентированные на желания адресанта, модифицированные формой сослагательного наклонения, что дает возможность заключить, что и в асимметричных отношениях РА «приглашение» в русском коммуникативном поведении не является угрожающим лицу.

\subsection{3. Взрослые}

В данной группе в разностатусных приглашениях наиболее частотным способом выражения является использование перформативных высказываний (65\%), чаще всего представленных в модели «(гоноратив) обращение + (местоимение) + перформатив + интенсификатор (дополнительная информация)», где информация в круглых скобках опциональна:

(50) Уважаемый Петр Иванович, пригламаю Вас на (мероприятие). Буду рад видеть вас среди гостей.

Помимо перформатива, относительно частотными (19\%) оказались условные конструкции с сослагательным наклонением «хотелось бы вас пригласить» / «хотела бы вас пригласить».

Наиболее продуктивными интенсификаторами являются высказывания, выражающие позитивные чувства приглашающего, подчеркивающие значимость для адресата принятия его приглашения.

(51) Уважаемый..! Приглашаю Вас на..! Буду рад Вас увидеть!

(52) Приходите, буду очень рада.

(53) Была бы очень рада вас видеть!

(54) Нам очень важно ваме присутствие.

(55) Мне было бы очень приятно.

(56) Приходите, пожалуйста, ко мне.

К единичным моделям относятся формальные приглашения:

(57) Разрешите пригласить Вас.

(58) Позвольте пригласить Вас.

(59) Прошу Bас посетить. 
Заметим, что именно в группе «Взрослые» в обеих подгруппах наиболее ярко проявилось использование модификаторов при обращении - как в равностатусном (маркер сближения «дорогой»), так и в разностатусном (маркер дистанцирования «уважаемый»).

В целом, как мы видим, репертуар реплик довольно ограничен (безусловно, допускаем употребление более разнообразных конструкций в реальной речи, с другими информантами).

Резюмируем результаты в виде таблицы.

Таблица 3

Выражение приглашения в разностатусном общении

\begin{tabular}{|l|c|c|c|}
\hline \multirow{2}{*}{\multicolumn{1}{|c|}{ Параметр }} & \multicolumn{2}{c|}{ Группа } \\
\cline { 2 - 4 } & Школьники & Студенты & Взрослые \\
\hline Императивные конструкции & $1 \%$ & $2 \%$ & $9 \%$ \\
\hline Вопросительные конструкции & $16 \%$ & $26 \%$ & $19 \%$ \\
\hline Сослагательное наклонение & $2 \%$ & $42 \%$ & $65 \%$ \\
\hline Перформативы & $81 \%$ & $30 \%$ & $51 \%$ \\
\hline Интенсификаторы & $39 \%$ & $51 \%$ & окказионально \\
\hline Митигаторы & $12 \%$ & $17 \%$ & окказионально \\
\hline Уточнение даты/времени & окказионально & окказионально & обращения \\
\hline Лексические особенности & $\begin{array}{l}\text { нейтральная лексика, } \\
\text { «мы»-приглашения }\end{array}$ & $\begin{array}{l}\text { обращения, описание } \\
\text { выгоды бенефицианта }\end{array}$ & . \\
\hline
\end{tabular}

\section{5. Выводы}

Анализ трех возрастных групп (школьники, студенты, взрослые) выявил общие тенденции и частные особенности формулировки приглашений в равнои разностатусном общении.

Равностатусные приглашения респондентов школьного возраста формулируются, в основном, прямым императивом и интенсификатором, либо императивом совместного действия. Отличительной характеристикой неформальности данной подгруппы является использование молодежного сленга как маркера внутригрупповой принадлежности (бро, го, дороу, погнали и др.). Разностатусные приглашения характеризуются использованием формулы обращение+перформатив, что свидетельствует о том, что в русской коммуникативной культуре перформатив не несет угрозы лицу и не ограничивает свободу действия. Субординативные отношения также показаны формулой обращения по имени-отчеству.

В группе «Студенты» равностатусные приглашения также формулируются с использованием императива и дополнительных элементов. Уточняющий элемент обычно следует в вопросительной форме и непосредственно уточняет возможность/желание (Придешь? Tbl свободна?). В данной группе частотны описания ситуации перед непосредственно приглашением. Здесь также встречается использование молодежного сленга (тупо почиллить, подкатишь?, хаюшки, хэй и др.).

Анализ результатов группы «Взрослые» в целом подтверждает общую тенденцию использования императива для равностатусного приглашения и перформа- 
тива - для разностатусного. Тем не менее, в данной подгруппе использование перформатива носит более широкий характер и в большей мере распространяется на равностатусное общение, чем в других равностатусных группах. В данной группе обращают на себя внимание элементы «сердечности» — в равностатусных приглашениях частотно обращение «дорогая», в разностатусных - эмфаза своего желания видеть приглашаемого (буду рад Вас видеть! Нам будет очень приятно Ваше присутствие).

Сопоставляя регистры организации речевого акта, видим, что для всех подгрупп (кроме группы 'взрослые + равностатусные') характерно широкое использование интенсификаторов, вопросительные/вопросительно-отрицательные высказывания более характерны для групп 'школьники', 'студенты'. Перформативы наиболее часто используются в разностатусных приглашениях всех анализируемых подгрупп (и довольно редко - в группах 'школьники + равностатусные', 'студенты + равностатусные').

Результаты проведенного анализа показывают, что как в формальных, так и неформальных приглашениях широкое использование находят интенсификаторы; перформативные высказывания наиболее характерны для формальных приглашений, а для неформальных приглашений любой возрастной группы императивные конструкции.

В целом полученные результаты позволяют заключить, что речевой акт «Приглашение» в русской лингвокультуре не является в той же степени угрожающим лицу, как, например, в британской или американской (см. Ларина, Щелчкова 2013; Ларина 2009 а, б; Щелчкова 2013, 2015 и др.). Эпиграф, приведенный в начале статьи, ярко иллюстрирует тот факт, что приглашение практически лишено показателей условности и неимпозитивности. Наши данные подтверждают ранее сделанные выводы (Ларина 2009 а, б; Larina 2015), о том, что в русской культуре, которая относится к коллективистскому типу (Larina et al. 2017 a, в), где ценятся общение и солидарность, предпочтение отдается прямому приглашению, допускается воздействие говорящего на адресата, что не нарушает принципов вежливости. Русские коммуниканты проявляют тенденцию к усилению приглашения, а не к его смягчению, предоставление выбора расценивается ими, скорее как неискренность (Leech \& Larina 2014: 14-15).

Подтверждается также идея о том, что коммуникативное поведение говорящего обусловлено тем, к какой национальной культуре относится коммуникант, какие нормы и конвенции приняты в обществе, частью которого он является (Власян 2016; Ларина 2009б; Прохоров, Стернин 2016; Culpeper \& Terkourafi 2017; Hofstede 2003; Samovar, Porter, McDaniel 2012; Vlasyan 2018; Wierzbicka 1991 и др.).

Результаты исследования носят ограниченный характер и не претендуют на полноту раскрытия материала в связи с ограниченной выборкой (группа «Школьники» представлена ограниченным возрастом, группа «Студенты» студентами преимущественно гуманитарных специальностей, группа «Взрослые» состояла в основном из лиц, имеющих высшее образование), тем не менее они дают новые данные о выражении приглашения в русской коммуникативной куль- 
туре и способствуют лучшему пониманию русской вежливости и стиля коммуникации. Они могут быть использованы в рамках межкультурной прагматики, межкультурной коммуникации, в переводческой и преподавательской практике.

(С) Г.Р. Власян, И.В. Кожухова, 2019 cc creative

https://creativecommons.org/licenses/by/4.0/

\section{СПИСОК ЛИТЕРАТУРЫ / REFERENCES}

Акишина А.А., Формановская Н.И. Выражение приглашения в русском языке // Русский язык за рубежом. 1968. № 3. C. 98 -107. [Akishina, A.A., Formanovskaya, N.I. (1968). Vyrazhenie priglasheniya v russkomyazyke (Invitations in Russian). Russkij yazyk za rubezhom. № 3. 98107. (In Russ)].

Власян Г.Р. Влияние культуры на коммуникативное поведение говорящего // Филологические науки. Вопросы теории и практики. 2016. № 10-1 (64). C. 42-45. [Vlasyan, G.R. (2016). Vlijanie kul'tury na kommunikativnoe povedenie govorjashchego (The impact of culture on communicative behaviour of the speaker). Filologicheskie nauki. Voprosy teorii i praktiki. № 10-1 (64). 42 - 45. (In Russ)].

Елизарова Г.В. Особенности национальной культуры: «время» и «пространство» по-русски // Universum: Вестник Гериеновского университета. 2009. C. 55-57. [Elizarova, G.V. (2009) Osobennostinacional'nojkul'tury: "vremya" i "prostranstvo" po-russki ("Time" and "Space" in Russian national culture). Universum: Vestnik Gercenovskogo universiteta. 55-57. (In Russ)].

Кожухова И.В. Интеррогативные косвенные речевые акты: реализация коммуникативной неимпозитивности (на материале английского и русского языков). Челябинск: ООО «Рекпол». 2012. 144 с. [Kozhuhova, I.V. (2012). Interrogativnye kosvennye rechevye akty: realizaciya kommunikativnoj neimpozitivnosti (na materiale anglijskogo i russkogo yazykov). (Interrogative indirect speech acts: communicative non-imposition (based on English and Russian). Chelyabinsk: OOO "Rekpol”. 144 (In Russ)]

Кожухова (Винантова) И.В. Структурно-синтаксические закономерности речевого акта «приглашение» в русском языке // Филологические науки. Вопросы теории и практики. 2010. № 3 (7). C. 41 -44. [Kozhukhova (Vinantova), I.V. (2010). Strukturno-sintaksicheskie zakonomernosti rechevogo akta "priglashenie" v russkom yazyke (Structural and syntactic peculiarities of invitations in the Russian language). Filologicheskie nauki. Voprosy teorii i praktiki. № 3 (7). 41-44. (In Russ)].

Ларина Т.В. Прагматика английского приглашения: межкультурный аспект // Жанры речи: Сборник научных статей. Саратов: Издательский центр «Наука», 2009а. Вып. 6. Жанр и язык. C. 307-317. [LarinaT.V. Pragmatika angliiskogo priglasheniya: mezhkul'turnyi aspekt (Pragmatics of English invitation: cross-cultural aspect). Zhanry rechi: Sbornik nauchnykh statei. Saratov: Izdatel'skii tsentr "Nauka", 2009. Vyp. 6. Zhanr i yazyk. 307-317. [In Russ)].

Ларина Т.В. Категория вежливости и стиль коммуникации: сопоставление английских и русских лингвокультурных традииий. М.: Языки славянских культур, 2009б. 507 с. [Larina, T.V. (2009) Kategoriya vezhlivosti i stil' kommunikacii: sopostavlenie anglijskih i russkih lingvokul'turnyh tradicij. (Category of Politeness and Communication Style: a Comparison of English and Russian Traditions of Communication) M.: Yazyki slavyanskih kul'tur, 2009. (In Russ)].

Ларина Т.В. Англичане и русские: Язык, культура, коммуникация. М.: Языки славянских культyp, 2013. 360 c. [Larina, T.V. (2013) Anglichane i russkie: Jazyk, kul'tura, kommunikacija. 
(The English and the Russians: Language, Culture, and Communication) Moscow: Yazyki slavyanskih kul'tur (In Russ)].

Ларина Т.В., Щелчкова Е.Б. Речевой акт приглашение и проблемы понимания: межкультурный аспект // Вестник Новосибирского государственного университета. Серия: Лингвистика и межкультурная коммуникация. 2013. T. 11. № 2. C. 73-79. [Larina, T.V., Shchelchkova, E.B. (2013). [Rechevoj akt priglashenie i problemy ponimaniya: mezhkul'turnyj aspekt. (Speech Act 'Invitation' and aspects of its Comprehension: Intercultural Aspect) Vestnik Novosibirskogo gosudarstvennogo universiteta. Seriya: Lingvistika i mezhkul'turnaya kommunikaciya. 2013. T. 11. № 2. 73-79. (In Russ)]

Прохоров Ю.Е., Стернин И.А. Русские: коммуникативное поведение. М.: Флинта, 2016. 328 с. [Prohorov Ju.E., Sternin I.A. Russkie: kommunikativnoe povedenie. (Russians: communicative behaviour). M.: Flinta, 2016. (In Russ)]

Щелчкова Е.Б. Речевой акт Приглашение в американских и русских коммуникативных культурах (результаты эмпирического исследования) // Вестник Российского университета дружбы народов. Серия: Лингвистика = Russian Journal of Linguistics. 2013. № 4. C. 109115. [Shchelchkova, E.B. (2013). Rechevoj akt Priglashenie v amerikanskih i russkih kommunikativnyh issledovaniyah. (The Speech Act of Invitation in the American and Russian Communicative Cultures (results of an empirical research)). Vestnik Rossijskogo universiteta druzhby narodov. Seriya: Lingvistika = Russian Journal of Linguistics, 4, 109-115. (In Russ)].

Bella, Spyridoula (2009). Invitations and politeness in Greek: The age variable. Journal of Politeness Research. Language, Behaviour, Culture, 5 (2), 243-271. doi: 10.1515/JPLR.2009.013.

Brown, Penelope \& Stephen Levinson (1987). Politeness: Some universals in language usage. Cambridge University Press.

Culpeper, Jonathan \& Marina Terkourafi (2017). Politeness and pragmatics. In: Culpeper, Jonathan, Michael Haugh \& Daniel Kádár (eds.) The Palgrave Handbook of Linguistic (Im)Politeness. Basingstoke: Palgrave, 11-39. doi: 10.1057/978-1-137-37508-7.

Ervin-Tripp, Susan (1976). Is Sybil There? The Structure of Some American English Directives. Language in Society, 5 (01), 25-66.

Hofstede, Geert (2003). Culture's Consequences: Comparing Values, Behaviors, Institutions and Organizations Across Nations. Thousand Oaks CA: Sage Publications.

Journal of Pragmatics (2018). Invitations and responses: the formation of actions across languages. Piera Margutti, Véronique Traverso, Liisa Tainio, Paul Drew (eds.) doi: 10.1016/j.pragma.2017.12.010.

Isaacs, Ellenand \& Herbert Clark (1990). Ostensible invitations. Language in Society, 19 (4), 493509. doi: $10.1017 / \mathrm{S} 0047404500014780$.

Kádár, Daniel (2017). Politeness, Impoliteness and Ritual. Maintaining the Moral Order in Interpersonal Interaction. Cambridge University Press. doi: 10.1017/9781107280465.010.

Lakoff, Robin (1972) Language in Context. Language, 48. № 4, 907-927.

Larina, Tatiana (2015). Culture-Specific Communicative Styles as a Framework for Interpreting Linguistic and Cultural Idiosyncrasies. International Review of Pragmatics, 7, 195-215. doi: $10.1163 / 18773109-00702003$.

Larina, Tatiana, Arto Mustajoki \& Ekaterina Protassova (2017a). Dimensions of Russian culture and mind. In Katja Lehtisaari and Arto Mustajoki (eds.) Philosophical and cultural interpretations of Russian modernisation. Series: Studies in Contemporary Russia. London / New York: Routledge, 7-19.

Larina, Tatiana, Vladimir Ozyumenko \& Svetlana Kurteš (2017b) I-identity vs we-identity in language and discourse: Anglo-Slavonic perspectives Lodz Papers in Pragmatics. 13 (1), 195-215. 
Leech, Geoffrey (1983). Principles of pragmatics. London and New York. Longman. doi: 10.1515/ip-2017-0013.

Leech, Geoffrey (2014). The Pragmatics of Politeness. Oxford, NY: Oxford University Press. doi: 10.1515/ip-2017-0013.

Leech Geoffrey \& Tatiana Larina (2014). Politeness: West and East. Russian Journal of Linguistics. (former Bulletin of the Peoples' Friendship University of Russia. Linguistics), 4, 9-34.

Locher, Miriam (2006). Polite behaviour within relational work: the discursive approach to politeness. Multilingua, 25 (3), 249-267.

Locher, Miriam (2013). Relational Work and Interpersonal Pragmatics. Journal of Pragmatics, 58, 145-149. doi: 10.1515/jplr.2005.1.1.9.

Mills, Sara (2003). Gender and Politeness. Cambridge University Press. doi: 10.1017/ CBO9780511615238.

Mills, Sara (2017). English Politeness and Class. Cambridge University Press. doi: 10.1017/9781316336922.007.

Samovar, Larry A., Richard E. Porter \& Edwin R. McDaniel (2012). Intercultural Communication: A Reader. Wadsworth / Cengage Learning.

Searle, John (1976). A classification of illocutionary acts. Language in Society. London, Cambridge University Press, $1-23$.

Sifianou, Maria (1992). Politeness Phenomena in England and Greece. Oxford, NY, Oxford University Press.

Suzuki, Toshihiko (2015). How Politeness Is Controlled in Invitations, Their Acceptances and Refusals in English: A Case Study in the U.K. The Cultural Review (Waseda Commercial Studies Association), 47, 69-87.

Terkourafi, Marina \& Daniel Kadar (2017). Convention and ritual. In: Culpeper, Jonathan, Michael Haugh \& Daniel Kadar (eds.). The Palgrave Handbook of Linguistic (Im)Politeness. Basingstoke: Palgrave, 171—195. doi: 10.1017/9781107280465.

Thomas, Jenny (1995). Meaning in Interaction: an Introduction to Pragmatics. L., N.Y.: Longman.

Vlasyan, Gayane (2018). Linguistic Hedging in the Light of Politeness Theory. WUT2018 IX International conference "Word, Utterance, Text: cognitive, pragmatic and cultural aspects". The European proceedings of social and behavioural sciences. 685-690. doi: 10.15405/epsbs.2018.04.02.98.

Watts, Richard J. (2003). Politeness. Cambridge, Cambridge University Press. doi: 10.1017/CBO9780511615184.

Wierzbicka, Anna (1991). Cross-cultural Pragmatics: the Semantics of Human Interaction. Berlin: Mouton de Gruyter.

Wolfson, Nessa (1981). Invitations, Compliments, and the Competence of the Native Speaker. International Journal of Psycholinguistics. 1981. Vol. 24 (8), 7-22.

\section{Словари / Dictionaries}

Кузнецов С.А. Большой толковый словарь русского языка. 1-е изд. СПб. Норинт, 1998. 1534 с. [Kuznecov, S.A. (1998) Bol'shoj tolkovyj slovar' russkogo yazyka. (Dictionary of the Russian Language) - 1 ed-n. SPb. Norint. (In Russ)]

Лингвистический энииклопедический словарь. М.: Сов. энцикл., 1990. 685 с. [Linguistic Encyclopedic Dictionary (1990). Moscow: Sov. Encikl. Publ. (In Russ)] 


\section{Article history:}

Received: 18 January 2019

Revised: 25 April 2019

Accepted: 09 June 2019

\section{История статьи:}

Дата поступления в редакцию: 18 января 2019

Дата принятия к печати: 09 июня 2019

\section{Bionotes:}

GAYANE R. VLASYAN is a PhD in Linguistics, Chair of the Department of Theory and Practice of the English Language at Chelyabinsk State University. She is a member of the Russian Cognitive Association. Research interests: pragmatics, politeness theory, conversational discourse, intercultural communication.

\section{Contact information: VlasyanGR@yandex.ru}

IRINA V. KOZHUKHOVA is a PhD in Linguistics, Associate Professor at Chelyabinsk State University. Research interests: pragmatics (theory of speech acts, theory of politeness, pragmatic competence), cultural linguistics, intercultural communication.

Contact information: vinantov@mail.ru

\section{Сведения об авторах:}

ГАЯНЭ РУБЕНОВНА ВЛАСЯН, кандидат филологических наук, доцент, заведующий кафедрой теории и практики английского языка Челябинского государственного университета. Сфера научных интересов: прагматика, теория вежливости, конверсационный дискурс, межкультурная коммуникация.

Контактная информация: VlasyanGR@yandex.ru

ИРИНА ВЛАДИМИРОВНА КОЖУХОВА, кандидат филологических наук, доцент кафедры теории и практики английского языка Челябинского государственного университета. Сфера научных интересов: прагматика (теория речевых актов, теория вежливости, прагматическая компетенция), лингвокультурология, межкультурная коммуникация.

Контактная информация: vinantov@mail.ru 